\title{
Erratum zu: Die digitale Konstellation. Eine Positionsbestimmung
}

\author{
Sebastian Berg • Niklas Rakowski • Thorsten Thiel
}

Online publiziert: 8. März 2022

(C) Der/die Autor(en) 2022

\section{Erratum zu:}

\section{Z Politikwiss 2020}

https://doi.org/10.1007/s41358-020-00207-6

Bei der Veröffentlichung dieses Beitrages wurden die Liste der Autoren inkorrekt wie folgt aufgeführt:

Sebastian Berg ${ }^{1} \&$ Niklas Rakowski ${ }^{1} \&$ Thorsten $_{\text {Thiel }}^{1}$ \& Forschungsgruppe Demokratie und Digitalisierung, Weizenbaum-Institut für die vernetzte Gesellschaft, Wissenschaftszentrum Berlin für Sozialforschung

korrekt musste sie aber so lauten:

Sebastian Berg${ }^{1}$ \& Niklas Rakowski ${ }^{1} \&$ Thorsten Thiel.

Der Originalbeitrag wurde korrigiert.

Open Access Dieser Artikel wird unter der Creative Commons Namensnennung 4.0 International Lizenz veröffentlicht, welche die Nutzung, Vervielfältigung, Bearbeitung, Verbreitung und Wiedergabe in jeglichem Medium und Format erlaubt, sofern Sie den/die ursprünglichen Autor(en) und die Quelle ordnungsgemäß nennen, einen Link zur Creative Commons Lizenz beifügen und angeben, ob Änderungen vorgenommen wurden.

Die Online-Version des Originalartikels ist unter https://doi.org/10.1007/s41358-020-00207-6 zu finden.

Sebastian Berg · Niklas Rakowski · Thorsten Thiel $(\bowtie)$

Forschungsgruppe Demokratie und Digitalisierung, Weizenbaum-Institut für die vernetzte

Gesellschaft, Wissenschaftszentrum Berlin für Sozialforschung, Hardenbergstraße 32, 10623 Berlin,

Deutschland

E-Mail: thorsten.thiel@wzb.eu 
Die in diesem Artikel enthaltenen Bilder und sonstiges Drittmaterial unterliegen ebenfalls der genannten Creative Commons Lizenz, sofern sich aus der Abbildungslegende nichts anderes ergibt. Sofern das betreffende Material nicht unter der genannten Creative Commons Lizenz steht und die betreffende Handlung nicht nach gesetzlichen Vorschriften erlaubt ist, ist für die oben aufgeführten Weiterverwendungen des Materials die Einwilligung des jeweiligen Rechteinhabers einzuholen.

Weitere Details zur Lizenz entnehmen Sie bitte der Lizenzinformation auf http://creativecommons.org/ licenses/by/4.0/deed.de. 